\title{
Neighborhood Access to Transit by Race, Ethnicity, and Poverty in Portland, OR
}

\author{
Brian S. McKenzie* \\ U.S. Census Bureau
}

\begin{abstract}
Scholarly discussions of accessibility and spatial mismatch largely ignore transit's role in linking vulnerable populations to opportunity. Yet as the nation's low-income population has become more suburban in recent decades, transit access may become an increasingly valuable, yet scarcer link to opportunity for those with the fewest resources and housing options. This study explores differences in transit access for neighborhoods with high concentrations of heavy transit users. Using data from the 2000 Census and the 5-year 2005-2009 ACS, it compares changes in transit access levels across neighborhoods with high concentrations of blacks, Latinos, and the poor in Portland, OR. Results show that Portland's neighborhoods of Latino concentration had the poorest relative access to transit. Further, levels of transit access declined for neighborhoods of black and Latino concentration during the study period.
\end{abstract}

\section{INTRODUCTION}

The pioneering work of John F. Kain (1968) focused the lens of urban scholarship on the increasing distance between job centers and neighborhoods of concentrated poverty. He proposed that the movement of jobs away from cities to expanding suburbs is particularly damaging to the economic prospects of poor and residentially segregated black workers, a concept that would become known as the spatial mismatch hypothesis (SMH). A wealth of literature supports variations of the SMH, demonstrating that racial residential segregation linked to discrimination in the housing market and decentralization of employment exacerbates group disparities in proximity to employment and labor market outcomes (Ihlandfeldt and Sjoquist 1998).

The SMH focuses on proximity to jobs, just one component of a broader set of problems characterized by unequal access to opportunity, goods, and services. In landscapes built to accommodate the automobile, group differences in access to amenities are largely rooted in differences in transportation options rather than spatial proximity. Mobility limitations are particularly inhibiting for the poor and racial and ethnic minorities, who have comparatively low auto ownership rates and disproportionately rely on public transportation (McKenzie and Rapino 2011; Tomer 2011). In recent decades these populations

Any views or opinions expressed in this article are those of the author and do not necessarily reflect those of the U.S. Census Bureau.

*Correspondence should be addressed to Brian S. McKenzie, SEHSD, U.S. Census Bureau, 4600 Silver Hill RD, Suitland, MD 20746; mckenzieb@gmail.com.

City E Community 12:2 June 2013

doi: 10.1111/cico.12022

(C) 2013 American Sociological Association, 1430 K Street NW, Washington, DC 20005 
have become more prevalent in suburbs, where poverty increased at a rate five times that of cities between 2000 and 2008 (Kneebone and Garr 2010), but where public transportation options are often lacking (Tomer 2012).

This study advances the discussion of mobility and accessibility by examining access to public transportation (transit) for neighborhoods (block groups) with high concentrations of populations that rely heavily on transit. For the Portland, OR, region, neighborhoods of high Latino concentration, high black concentration, and concentrated poverty are identified separately, and transit access is compared across neighborhood types using Poisson regression. Transit access is assessed across two time periods using public data from the 2000 Census and multi-year American Community Survey (ACS) estimates representing the 5-year period from 2005 to 2009 (treated as a point estimate). For brevity, the term "segregated" is used to describe block groups of interest, but they are perhaps more appropriately characterized as areas of high concentration for a given group. The tool used to identify residential clustering, the Moran's $I$, identifies areas of high concentration relative to the entire metro. Due to the region's small overall population of each of the groups of interest, relatively few block groups contain a majority of each subgroup. These areas of high concentration for certain groups, though not necessarily highly segregated, still represent areas of relative disadvantage in housing choices.

Beyond its substantive findings, this paper makes important methodological contributions to existing literature. It uses a neighborhood-level transit access indicator based on the average level of access of multiple neighborhood housing parcels rather than a single neighborhood point. It also uses a sidewalk and transit network-based distance measure rather than the commonly used straight line measure. Transit access information is then linked to demographic information for each block group. Finally, rather than providing only a snapshot of transit access, this study captures changes in neighborhood access over time, specifically, over the 2000s, when the Portland region experienced rapid urban gentrification (Shaw and Sullivan 2011) and rising central city housing costs (Miles and Song 2009).

The study area and time periods were selected for practical and theoretical reasons. The years selected represent relevant periods for which sufficient and comparable demographic and spatial data are available. This period also provides insight into how the Portland region has changed since its Latino population increased considerably and gentrification took off. The Portland landscape provides an opportunity to explore one of the growing set of metropolitan areas that have experienced increased suburban poverty and minority representation alongside an economically vibrant urban core with an extensive transit system.

\section{LITERATURE REVIEW}

\section{RISING SUBURBAN POVERTY AND DEMOGRAPHIC SHIFTS ACROSS METROPOLITAN AREAS}

The 2000s marked the first period in which more of the nation's poor lived in suburbs than in cities. In several metropolitan areas, increases in suburban poverty rates exceeded those of their central city counterparts (Kneebone and Garr 2010). Suburban poverty rates and the factors that influence them vary considerably across metropolitan areas. In several high-growth suburbs, declining home values, high foreclosure rates, and labor 
market disruptions contributed to narrowing wealth gaps between suburbs and their central city counterparts (Lucy 2010). Within metropolitan areas, poverty has also become more concentrated (Kneebone, Nadeau, and Berube 2011). Between 1970 and 2007, the percentage of families living in neighborhoods of concentrated affluence or poverty increased from 15 percent to 31 percent (Reardon and Bischoff 2011). The increased presence of the foreign born in the suburbs has also contributed to rising poverty rates, as foreign-born suburban residents have lower average incomes than their native-born counterparts (Singer 2010).

Increased demand for services in conjunction with declines in revenue for social service providers has strained resources for the poor across suburban communities (Allard and Roth 2010). The changing sociodemographic makeup of suburbs presents new planning opportunities and challenges, including those associated with transportation and mobility. Compared to their more compact urban counterparts, transit availability in outlying communities is relatively poor in most metropolitan areas (Tomer 2012). Suburban areas often do not meet population or commercial density levels that efficiently support transit. As a growing number of economically disadvantaged Americans find themselves in suburbs with few transit-oriented travel options, mobility will become a critical local constraint on opportunity.

The 2010 Census revealed that suburbs have also become more racially and ethnically diverse since 2000, largely due to recent suburban black and Latino population gains (Frey 2011). Despite large suburban population increases for blacks and Latinos, the severity of residential segregation for these groups changed little during the decade (Logan and Stults 2010). Black segregation from non-Hispanic whites remains the most severe, but declined slowly between 2000 and 2010 from a dissimilarity score of 0.64 to 0.59. Latinos, although less segregated than blacks, experienced similarly modest declines with a dissimilarity score of 0.51 in 2000 and 0.48 in 2010 (Logan and Stults 2010). A rich body of research has linked persistent segregation along lines of race, ethnicity, and income to deleterious neighborhood characteristics such as poor school quality, reduced employment opportunity, and the absence of important neighborhood institutions such as health-care facilities and mainstream grocery stores (Massey and Denton 1993; Wilson 1996; Nechyba 2003).

Racial and economic residential clustering patterns have taken on a more patchworklike form in recent decades (Alba et al. 2010; Dwyer 2010; Reardon and Bischoff 2011). Characteristics of suburban racial or ethnic enclaves sometimes closely mirror their urban counterparts along several measures of economic well-being (Newbold and Spindler 2001; Liu 2009; Alba et al. 2010). Blacks and Latinos in suburbs are heavily concentrated in low-income communities, particularly older inner-ring suburbs, where Latinos make up the fastest growing population group (Holzer and Stoll 2007). Several questions remain with respect to the unique ways in which the suburban landscape, its mix of institutions, and transportation infrastructure will shape the economic opportunities of the increasing number of low-income suburban residents.

\section{ACCESSIBILITY, MOBILITY, AND TRANSIT ACCESS}

Numerous studies provide evidence that blacks and other disadvantaged groups face spatial barriers in accessing job centers in newer automobile-oriented suburbs (Ihlanfeldt 
and Sjoquist 1998; Stoll et al. 2000; Wagmiller 2007). Suburban status appears to have some positive effect on labor market outcomes for some groups, particularly immigrants (Liu 2009). Still, blacks and Latinos living in the suburbs disproportionately reside in communities with relatively poor rates of job growth (Luce, Orfield, and Mazullo 2006; Raphael and Stoll 2010). The degree and nature of spatial mismatch varies considerably across populations (Covington 2009), urban form (Stoll 2006), foreign born status (Yang Liu and Painter 2012), and the interaction of gender with other characteristics (Parks 2004). Overall, these studies find that race remains a salient determinant of job access (Ihlanfeldt and Sjoquist 1998; Stoll 2006).

A better understanding of variation in transportation options should inform discussions of group differences in accessibility and changes in mobility limitations of the poor. The poor are more likely than the nonpoor to live in households with no vehicles (Tomer 2011) and expend a greater portion of their income on transportation costs (Roberto 2007). Several studies find that increased automobile access positively influences labor market outcomes such as employment rates among welfare recipients (Ong and Houston 2002) and reduced commute time (Taylor and Ong 1995). For inner city residents, automobile access is also shown to have a stronger influence on job access than spatial proximity to jobs (Kawabata and Shen 2007; Grengs 2010). These findings are not surprising, as only less than one-third of metropolitan jobs are accessible by transit (Tomer 2012).

A small number of studies assess transit coverage across metro areas and link it to labor market outcomes. Tomer (2012) finds that, across large metropolitan areas, the typical job is accessible by transit to only 27 percent of the workforce, and accessibility is even lower in the suburbs, where transit coverage is typically poor. Transit's linkage to jobs is poorest for industries in which low-skilled workers are disproportionately employed, including construction, agriculture, and manufacturing. Improvements in transit access have been linked to improvements in labor market outcomes such as employment rates and hours worked (Sanchez 1999; Alam 2005) and reduced wage inequality at the metropolitan area level (Sanchez 2002). For several large metropolitan areas, Stoll, Holzer, and Ihlanfeldt (2000) find a greater number of minority workers employed at firms located along transit routes. Holzer and Quigley (2003) find that in San Francisco, major investment in rail service enhancements produced subsequent gains in the employment rates of inner-city minorities at the suburban firms surrounding newly opened stations, many of which were in neighborhoods that were previously inaccessible to inner city residents.

These results are in contrast to studies concluding that transit access has a less pronounced effect on employment outcomes in metropolitan areas (Sanchez, Shen, and Peng 2004). Several studies find that automobile access is a stronger predictor of labor market outcomes than transit access (Cervero, Sandoval, and Landis 2002; Kawabata and Shen 2007). Across a diverse set of metropolitan areas, more neighborhoods enjoy access to business establishments by automobile than they do by transit, a function of transit's limited coverage (Tomer 2012). These varied outcomes reflect variations in the role transit plays across communities and populations. Despite mixed results regarding transit's link to specific socioeconomic outcomes, transit undoubtedly provides low-cost access to essential goods, services, and institutions for vulnerable populations such as the poor, the disabled, or those too old or too young to drive. For example, several studies link 
increased transit access to increased grocery store access (Grengs 2001; Neckerman et al. 2009; Bader et al. 2010).

Given the low-income population's relatively high dependence on transit, researchers should devote increasing attention to the availability of affordable housing in transitoriented neighborhoods. Recent studies suggest that affordable housing situated near transit has become scarce in several cities, including those where transit plays an integral role in the community's transportation network (Leinberger and Alfonzo 2012). Becker, Bernstein, and Young (2013) found that transit-accessible real estate retained more value during the housing crisis of the late 2000s than more automobile-oriented real estate. Kahn (2007) finds that gentrification, as indicated by increased home prices, occurred more rapidly in centralized neighborhoods with investment in "walk and ride" transit compared to automobile-oriented "park and ride" transit investment. A survey conducted by the American Planning Association found the availability of transit to be one of the highest priorities for respondents' ideal community (APA 2012), suggesting that transit's appeal is not limited to those who depend on it due to financial constraints. The research presented here captures the important relationship between transportation infrastructure and ever-shifting residential patterns of the populations that rely most heavily on transit. It examines this relationship in a region that has experienced marked shifts in the spatial distribution of its population along lines of race, ethnicity, and income.

\section{THE STUDY AREA}

The Portland region is widely known for its land use policies aimed at limiting sprawl, strengthening the urban core, and fostering a multi-modal transportation infrastructure. Several central city neighborhoods in Portland experienced considerable disinvestment during the 1970s and 1980s, but during the decades that followed, a series of regionallevel redevelopment and growth management initiatives helped mitigate socioeconomic disparities between Portland and its suburbs (Phillips and Goodstein 2000). The population of the Portland-Vancouver-Beaverton, OR-WA metropolitan area (Portland metro area hereafter) increased from just under 1.5 million people in 1990 to more than 2.2 million in 2010 (U.S. Census Bureau 2011). The region's urban growth boundary (UGB) has steered much of this growth within or near downtown Portland.

The region has invested heavily in transit, which works in concert with the UGB to benefit from and reinforce an urban fabric of moderate-to-high population density, including new transit-oriented development within and outside the central city (Song and Knaap 2004). The region's light rail system, the Metropolitan Area Express (MAX), has been especially influential in guiding residential and commercial development. The MAX is considered a model among light rail systems for its frequency, speed, and ability to reach an extensive set of the region's neighborhoods (Thompson and Brown 2012). These characteristics place the Portland area at the forefront of providing transit access with implications for group differences in mobility compared to other metropolitan areas.

Commuting patterns in the region reflect its investment in multimodal transportation. Fewer than 60 percent of Portland's workers drove alone to work in 2010, including 12 percent of transit commuters (U.S. Census Bureau 2012). Success in this area extends beyond the city of Portland and is evidenced by the relatively high rates of transit usage, 
walking, and bicycling within the metro area's inner suburbs such as Beaverton and Gresham. This is notable because transit usage rates for suburbs are often considerably lower than their central city counterparts.

The region has demonstrated continued commitment to transit investment, but budget shortfalls prompted reductions in some rail and bus service in 2008 and in subsequent years (TriMet 2012). The transit authority has stated that service cuts were aimed at bus routes with low ridership, those that duplicate other routes, and those that do not disproportionately impact low-income communities (TriMet 2012). Portland eliminated its downtown Free Rail Zone, cut bus service for some outer suburban lines, and reduced frequency for some MAX lines. These service reductions have occurred alongside continued investment in long-term projects, including rail expansions. An extension of the MAX green line opened in 2009 and a streetcar line that connects the East and West side of the city opened in 2012. It remains to be seen whether the region's shifting demographic patterns will play a stronger role in affecting transit access for low-income communities than changes in transit service.

\section{GENTRIFICATION AND RESIDENTIAL SETTLEMENT PATTERNS IN THE PORTLAND REGION}

Since the 1990s, capital investment and population growth fueled economic revitalization within several previously economically depressed Portland neighborhoods, altering the relative spatial distribution of wealth. The degree of demographic shift that has occurred is evidenced by the dramatic increase in the percentage of Portland's population aged 25 and older with a bachelor's degree or higher, which increased from about 26 percent in 1990 to 42 percent by 2010 (U.S. Census Bureau 2011). Employment centers, including several high-tech firms, have located along Portland's rail corridor, fostering considerable development (Mayer 2005). Figure 1 shows the study area and the distribution of concentrated poverty within the UGB in 2000 and 2005-09. In 2000, the majority of poor enclaves were found near the city center or among a small number of suburbs such as Gresham. By 2005-09, the number of high-poverty block groups had increased in several outlying communities. Still, the region's overall poverty rate remained relatively low, at just under 12 percent in 2005-09.

Residential patterns in Portland are rooted in a complex history of discriminatory real estate practices such as redlining and predatory lending. These worked in concert with "white flight" to concentrate black settlement into a small number of neighborhoods in Northeast Portland. Neighborhoods such as Boise-Elliot suffered from disinvestment for much of the latter half of the 20th century, but these centralized neighborhoods began to attract considerable investment from outsiders during the early 1990s (Sullivan 2007; Shaw and Sullivan 2011). Figure 2 shows the spatial distribution of block groups with black and Latino concentrations (separately) across the 2000s. Enclaves of both groups decentralized over the study period.

In 2000, the Portland metro area contained a single notable, highly localized cluster of block groups of black concentration, east of the Willamette River. Several social and economic forces typically associated with gentrification, including an influx of young white professionals, have transformed the racial and economic characteristics of the historically black inner-Northeast Portland. Over the 2000s, areas of black concentration became less 

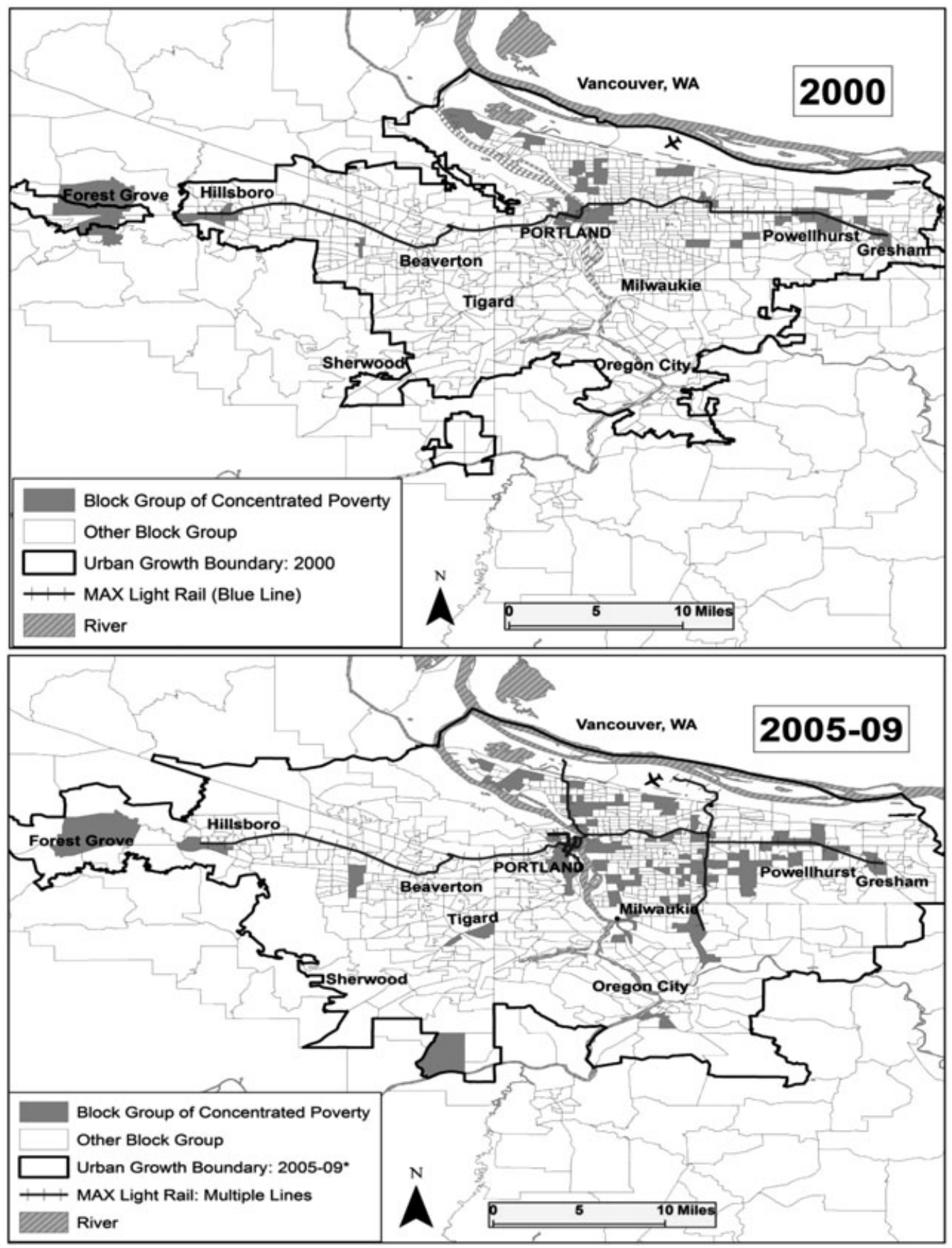

FIG. 1. Spatial distribution of block groups of concentrated poverty within Portland, OR, urban growth boundary: 2000 and 2005-09.

Notes: *Represents 2008 UGB; lighter lines are Census block groups; clusters represent at least two contiguous block groups. 


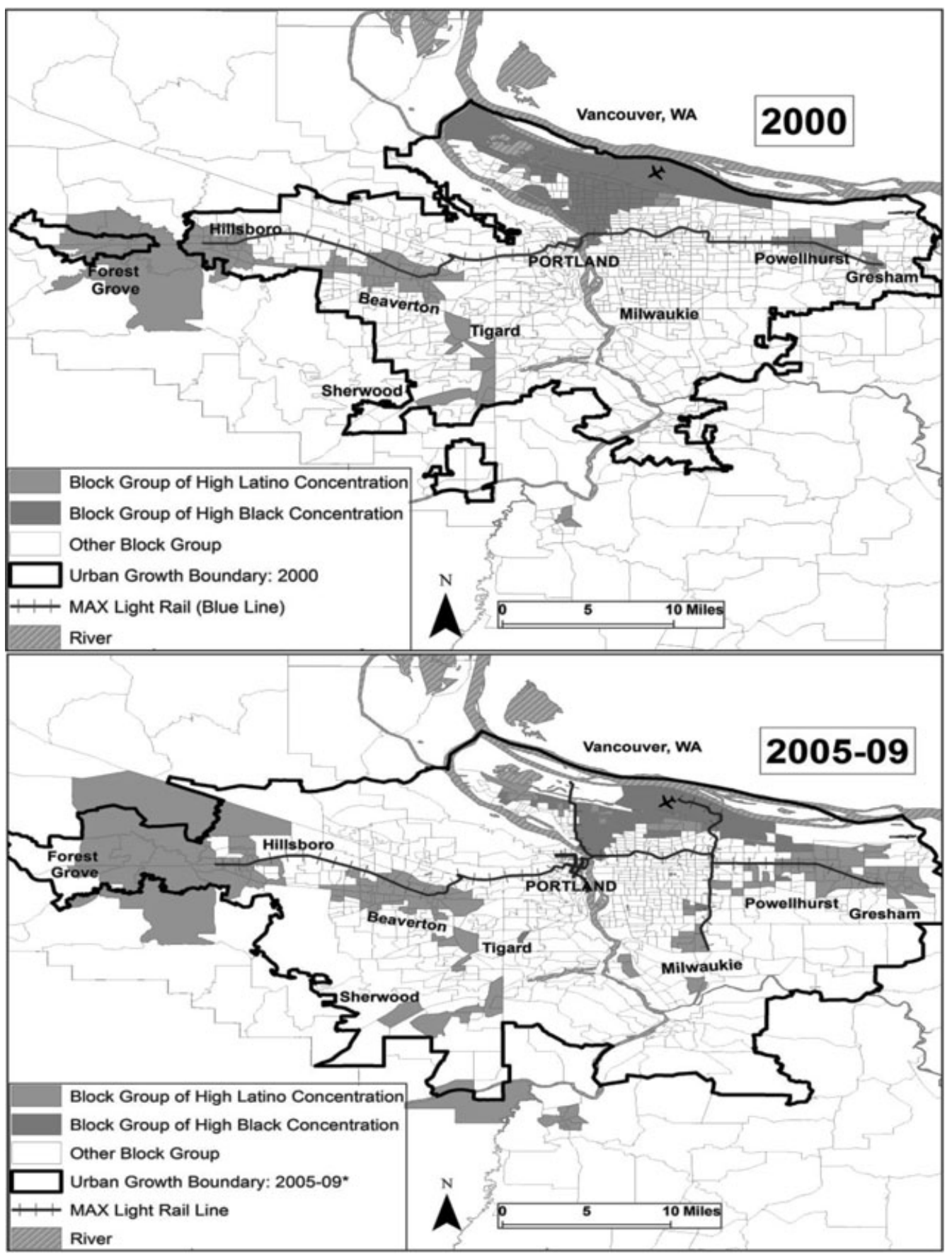

FIG. 2. Spatial distribution of block groups of Latino concentration and black concentration within Portland, OR, urban growth boundary: 2000 and 2005-09.

Notes: *Represents 2008 UGB; lighter lines are Census block groups; clusters represent at least two contiguous block groups. 
centralized. The proportion of the Portland metro area's black population living outside of the City of Portland increased from about 37 percent in 2000 to about 43 percent in 2010 (U.S. Census Bureau 2011). Blacks made up only between 2.0 and 3.0 percent of the Portland metro area's population in any given decade between 1980 and 2010, but black segregation is relatively high for a metro area of its size and racial composition. The dissimilarity index for blacks in the Portland metro area increased from 47.4 percent in 2000 to 51.4 percent in 2005-09 (Logan and Stults 2010). The Economist (March 31, 2011) describes these demographic shifts.

[In Portland and Seattle] blacks were squeezed by restrictive property covenants and racial prejudice into a small but highly visible central district-black-majority islands in a white sea. By 2010 the islands had largely gone. Seattle and Portland had become "smart cities", magnets for hordes of young, highly educated and highly paid newcomers, most of them white and childless. Hungry for "diversity" and rushing into relatively rundown black neighbourhoods, they snapped up the only housing bargains left.... As gentrification gathered pace, property prices exploded.

White migration to the central city coupled with black decentralization may foster some degree of integration as residential shifts occur, but this may reflect a brief period of transition more than stable integration. Ellen, Horn, and O'Regan (2012) find that relatively few newly integrated black central city neighborhoods remained integrated between 1990 and 2010. As the gentrification process in Portland matures, longer-term residential patterns may become clearer. The slight increase in the Portland metro area's dissimilarity index also suggests that the degree of segregation in emerging areas of black concentration may be comparable to that of more established centralized areas.

Beginning in the 1980s, Latino immigration to the region increased notably, making Portland one of several "new Latino destinations," places that have recently seen rapid increases in their Latino populations, but have had little prior Latino settlement. Latinos made up only 2 percent of the metro area's population in 1980, but increased to over 7 percent by 2000, and almost 11 percent by 2009 (U.S. Census Bureau 2011). Latino enclaves in the region are more decentralized than those of blacks. In 2010, more than three-quarters of the metro area's Latinos lived in suburbs, where many Latino newcomers initially settled (U.S. Census Bureau 2011). As overall population growth increased during the 1990s, the construction, service, and other sectors attracted an increasing number of Latino workers. Facing a tight urban housing market upon arrival many Latino newcomers settled in peripheral communities such as Forest Grove, Hillsboro, and Gresham (Figure 2). Hillsboro's Latino population grew from 11 percent to 23 percent between 1990 and 2010 (U.S. Census Bureau 2012). As the Latino population increased across the 2000s, so did the number of block groups of high Latino concentration. Several new enclaves in 2005-09 are extensions of more established enclaves that existed in 2000, particularly those in Gresham and in western suburbs. Latino segregation remains low, but increased over the 2000s from 35.4 percent in 2000 to 37.9 percent in 2005-09 (Logan and Stults 2010).

While the region has served as a model for its commitment to providing an extensive and efficient transit system, unexplored questions remain regarding relative levels and benefits of transit access of various population groups. This is true for transit investment in general, not just for Portland. In 2004, a new light rail line opened north of downtown 
Portland, improving the link between downtown and several historically black neighborhoods. A wide range of community residents enjoys improvements in transportation infrastructure and other forms of capital investment, either directly or as externalities, but concomitant increases in neighborhood costs have adversely affected some longtime residents (Shaw and Sullivan 2011; Sullivan and Shaw 2011). Homeowners may benefit from rising real estate prices, but renters must face rising costs or move to a less expensive neighborhood. The research reported below addresses the extent to which such neighborhood changes influence the transit access of specific groups.

\section{METHODS}

This study contributes to the general body of neighborhood access literature by addressing several common methodological limitations associated with small scale simulations of the built environment. These include inadequate treatment of travel obstructions and failure to capture neighborhood trends due to assessing only one point in time. This study offers an innovative technique for measuring neighborhood transit access.

\section{DATA AND EXTENT OF STUDY AREA}

Block groups are the units of analysis and serve as proxies for small neighborhoods. Along with a variety of geographic information systems (GIS) data layers for boundaries and transportation infrastructure, I use demographic block group data from the Census 2000 long-form, and from 2005-09 ACS 5-year estimates. The study area is limited to block groups within Clackamas, Multnomah, and Washington Counties (Oregon) that have any part falling within the Portland UGB, including 823 block groups for the Census 2000 analysis, and 832 for the 2005-09 ACS analysis. Block groups outside of the UGB differ notably from those inside the UGB by population size, density, and land use type, and are not appropriate for such an analysis. Public transportation infrastructure outside the UGB is also quite limited. The selection of the block group level balances geographic scale and sociodemographic information. Census blocks are the smallest unit for which aggregated Census data are publicly available, but offer only basic demographic characteristics. Tracts offer more detailed demographic information, but are larger than block groups and probably miss household socioeconomic homogeneity across smaller geographic units.

\section{CONSTRUCTION OF THE DEPENDENT VARIABLE MEASURING NUMBER OF ACCESSIBLE TRANSIT ROUTES}

The construction of several variables relies upon GIS spatial analysis tools. The dependent variable, transit route choice, serves as an indicator of transit access for the average household in a block group. It is measured by the network-level walking distance from each housing parcel to nearby transit stops, calculated with ArcGIS Network Analyst, a network-based spatial analysis routing tool. The study area transportation network is simulated using GIS layers associated with housing parcels, the sidewalk network, and stops for the region's three principal transit network components: bus, light rail, and streetcars. The study employs two sets of GIS transit data (obtained from Metro of Portland) reflecting the region's transit system in the years 2000 and 2009. 
Most disciplines commonly capture access to amenities with a straight-line (Euclidean) distance measure between an origin point representing a neighborhood and a destination point representing the amenity of interest. This technique is limited in several ways. First, this method only accurately reflects the travel distance of residents who happen to live near the origin point, missing the varied household experiences across different parts of the same neighborhood. For example, the level of transit access of the handful of households located a block away from the centroid will be adequately represented by that centroid, but the considerable amount of walking required to reach transit for households located far from the centroid is not accounted for. Second, the Euclidean distance technique underestimates travel distance by failing to account for directional turns that occur when traversing real built environments. The transit access method employed in this study improves on prevailing techniques in several ways.

Using a sidewalk GIS layer, the network walking distance is measured between each household within a block group and nearby transit stops. For each block group these household distances are averaged to arrive at a single block group transit access measure that takes into account the transit experiences of households within the entire extent of the block group. Light rail or streetcar stops are considered accessible within onehalf of a mile, and bus stops are considered accessible within one-third of a mile. The number of transit routes associated with each accessible stop is then summed for each housing unit. For each block group, the final value of transit route choice represents the average number of accessible transit stops for all housing units in a given block group. Transit walking distance thresholds vary considerably across studies, with one-fourth and one-half mile thresholds most commonly used (Grengs 2001; Neckerman et al. 2009). In the absence of a clear research standard, this project uses one-third of a mile (network distance) for bus stops and one-half mile for rail stops. These network-based thresholds are more conservative than their Euclidean counterparts because they account for turns. A small number of U.S.-based studies have employed a street network approach (see Raja, Ma, and Yadav 2008; Sparks, Bania, and Leete 2011) or a kernel density approach (see Neckerman et al. 2009) to measuring access to amenities. As GIS techniques continue to improve, such approaches will surely become more prevalent.

This study counts each transit route direction independently for every stop in order to account for the possibility of one or two directions of travel, but only once if the stop is at a route terminus. This methodology also accounts for the number of transit lines at a given stop, a fundamental improvement over prevailing transit access measurement techniques. Similar to other studies, it does not account for differences in route schedules, which serve as important indicators of a stop's utility. Retroactive route schedule information representing the study period was not available for all routes. The study also does not account for differences in parking availability or bicycle access to transit stops. Even with such limitations, the unique construction of this project's dependent variable, transit route choice, addresses many of the prevailing methodological challenges to measuring neighborhood-level transit access.

\section{EXPLANATORY VARIABLES}

Explanatory variables used to predict transit access include those suggested by previous research within the fields of geography, urban planning, and sociology (Table 1). Population density and neighborhood jobs are outcomes of land use and built environment controls. 
TABLE 1. Variables in the Study

\begin{tabular}{|c|c|c|}
\hline Dependent Variable & Description and Measurement & Source \\
\hline Transit route choices & $\begin{array}{l}\text { Average of total number of routes accessible by each housing } \\
\text { parcel in block group (sidewalk network distance based) } \\
\text { within } 1 / 3 \text { mile from nearby bus stops, and } 1 / 2 \text { mile from } \\
\text { rail and streetcar stops }\end{array}$ & $\begin{array}{l}\text { Transit } \\
\text { infrastructure } \\
\text { data from Metro } \\
\text { of Portland }\end{array}$ \\
\hline Independent Variable & Description and Measurement & Sources \\
\hline Population density & Persons per acre in block group & 1,2 \\
\hline Neighborhood jobs & Total number of primary jobs in block group & 3 \\
\hline Working age & Percent workers in a block group ages $16-64$ & 1,2 \\
\hline Educational attainment & $\begin{array}{l}\text { Percent with postsecondary education for population } 25 \text { years } \\
\text { and over }\end{array}$ & 1,2 \\
\hline Renters & Percent occupied housing units rented & 1,2 \\
\hline Zero-vehicle households & Percent occupied households with zero vehicles & 1,2 \\
\hline Latino segregation & $\begin{array}{l}\text { Block group of Latino concentration }=1 \text {; other block } \\
\text { group }=0 \text {; based on Moran's } I \text { clustering technique for } \\
\text { percent of total block group population that is Latino* }\end{array}$ & 1,2 \\
\hline Black segregation & $\begin{array}{l}\text { Block group of black concentration }=1 \text {; other block group }= \\
0 \text {; based on Moran's I clustering technique for percent of } \\
\text { total block group population that is black* }\end{array}$ & 1,2 \\
\hline Concentrated poverty & $\begin{array}{l}\text { Block group of concentrated poverty }=1 \text {; other block } \\
\text { group }=0 \text {; based on Moran's } I \text { clustering technique for } \\
\text { percent of total block group population below poverty line* }\end{array}$ & 1,2 \\
\hline
\end{tabular}

Source 1 = Census 2000, SF3; Source 2 = ACS 5-year 2005-2009; Source 3 = LEHD Program, U.S. Census Bureau.

*The index measures the degree to which each block group's proportion of each racial/ethnic group is similar to the proportion of surrounding block groups relative to the mean of the entire study area.

Increases in both measures are generally associated with increased transit efficiency and availability. The predictive effect of zoning was tested in earlier models, but found to be highly correlated with population density, as is expected given their inherent relationship. Further, there are limited spatial data on zoning that are comparable across periods. There is evidence that, compared to other metro areas, Portland's regional zoning patterns are relatively accommodating to multi-family housing units, which contributes to more economically integrated neighborhoods (Chakraborty et al. 2010).

Younger workers, renters, people without vehicle access, nonwhites, and the poor have disproportionately high rates of transit usage (McKenzie and Rapino 2011). Thus, we control for four socioeconomic variables: percent working age population, percent postsecondary education, percent renters, and percent households with no vehicle. These variables are also linked to the three predictor variables of interest, dichotomous indicators of segregated Latino neighborhood, segregated black neighborhood, and high poverty neighborhood. The relationship between the explanatory high concentrations of blacks, Latinos, and the poor may vary across cities and may be related to the quality and utility of local transit. If these groups face greater housing market barriers, then obtaining transit-accessible housing in a city where transit access positively correlates with real estate prices (such as New York or Washington, DC) may be more difficult than obtaining it in places where only a small percentage of the population uses transit. Although transit development planners sometimes deliberately accommodate high-poverty neighborhoods, other neighborhood characteristics may largely determine the relationship between the poor and transit infrastructure. The socioeconomic controls help to isolate the direct influence of the three population concentration measures. 
Percentage thresholds for high-poverty neighborhoods and those of black and Latino concentration are based on the local Moran index (Moran's $I$ ). Moran's $I$ is a local indicator of spatial autocorrelation that relates the concentration of a neighborhood population characteristic to that of surrounding neighborhoods. For this analysis, it measures the degree to which each block group's proportion of a given subpopulation (Latinos, for example) is similar to the proportion of that population for nearby block groups. The measure uses a group's prevalence for the entire study area as a benchmark for comparison of a group's prevalence within each block group. Block groups that are adjacent to one another and have high proportions of a given group are then identified as a cluster.

Block groups of "high concentration" for blacks, Latinos, and the poor may not contain a majority of a given group because the Moran's $I$ benchmarks used for each measure are relatively low for the Portland metro area. In 2005-09 about 12 percent of the Portland metro area population was in poverty, about 3 percent of the population was black and about 10 percent was Latino. Among the block groups identified by the Moran's $I$ procedure, the 5 percent with the lowest group representation were omitted from the analysis because, although they had a higher percentage of a given group than the city as a whole, they were overwhelmingly white neighborhoods. This resulted in neighborhoods identified as having "high" concentrations of a given group having a minimum of 18 percent group representation. Block groups identified as areas of high Latino and high black concentration are categorized as segregated for the population group with the highest percentage of the block group's population (there were 9 instances of this).

\section{MODEL SPECIFICATION}

The distribution of the dependent variable, transit route choice, is nonnormal and positively skewed. Across block groups, the count of accessible transit routes is clustered around low values, making the measure unfit for ordinary least squares (OLS) regression. Instead, Poisson regression is used, as it employs a maximum likelihood approach more suitable to predict transit route choice. This approach estimates the logarithm of the change in the expected value of the dependent variable, transit route choice, as a function of the independent variables. For easier interpretation, Poisson regression coefficients are converted from a change in the logs of expected counts to incidence rate ratios (IRRs), or risk ratios. The IRR may be interpreted as the rate at which an event occurs across time or, in this case, across space (block groups). More specifically, it is the log of the ratio of the expected count of accessible transit routes across a one unit change in the predictor variable (the variable estimated at $\mathrm{x}$ relative to $\mathrm{x}+1$ ). IRR values of 1 indicate no change in the likelihood of the event's occurrence, while IRRs greater than 1 indicate an increased likelihood of the event's occurrence.

\section{RESULTS}

\section{DESCRIPTIVE RESULTS}

Overall, block groups in 2000 showed a higher number of average accessible transit routes than those in 2005-09, at 9.5 and 6.9 routes, respectively (Table 2 ). This difference could be the result of several factors, including some service reductions that began in 2008, mostly for bus routes. Service reductions in the form of less frequent daily service were 
NEIGHBORHOOD ACCESS TO TRANSIT

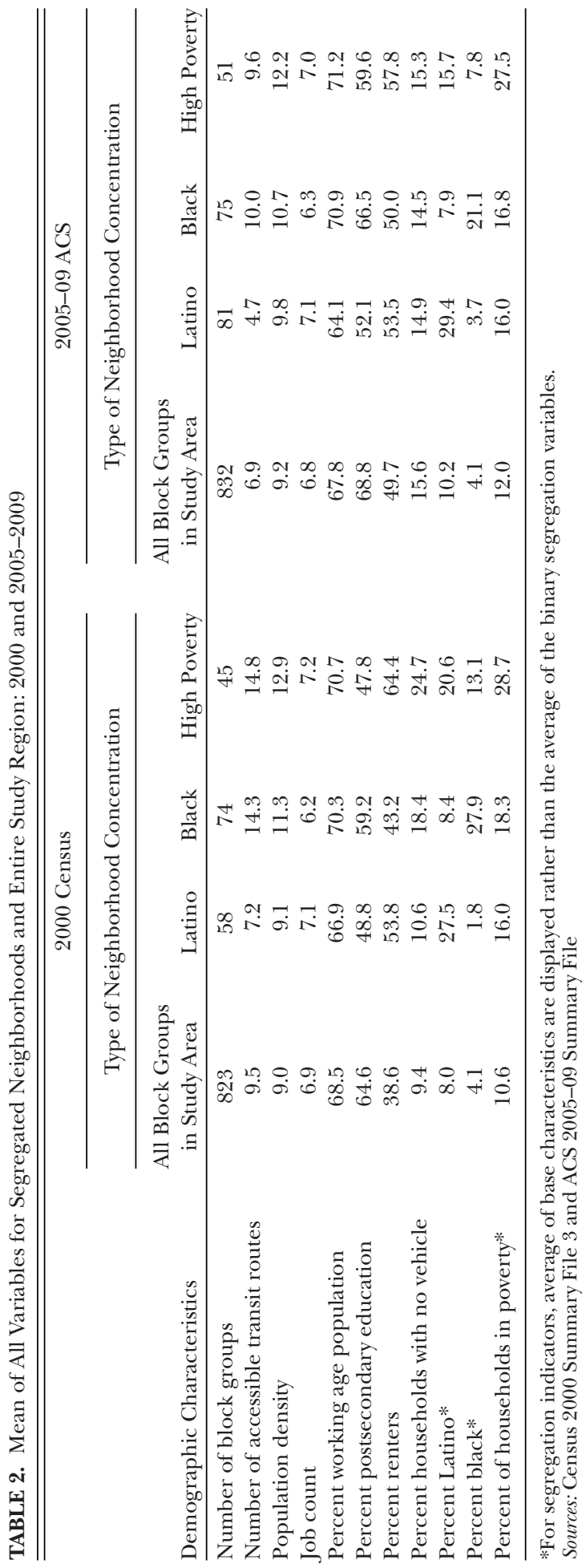


more common than route cuts. The addition of several more peripheral block groups within the UGB (not well served by transit) also may have contributed to the decline in average accessible routes. This effect simply represents a boundary change that creates a statistical reduction in transit access and may not reflect real service cuts. Block groups of high black concentration showed the highest average number of transit routes for both 2000 and 2005-09, at 14.3 and 10.0 routes, respectively, but black neighborhoods also showed the sharpest declines in the average number of transit route choices between periods. Accessible transit routes for Latino neighborhoods also changed substantially from 7.2 to 4.7. Poor neighborhoods experienced only a slight reduction in accessible transit routes across the decade, from 12.9 to 12.2 .

For all three socioeconomic dimensions of segregation-percent black, percent Latino, and percent in poverty-representation of each respective group as a percentage of total block group population is relatively low, even among block groups where these characteristics are concentrated. Such block groups should not necessarily be viewed as highly "segregated." Rather, they are areas where racial and ethnic minorities and the poor are represented in high proportions relative to the entire study area. Block groups of Latino concentration, considered in aggregate, had an average of 27.5 percent Latinos in 2000. This increased to 29.4 percent Latino in 2005-09, an expected result given sharp increases in the region's Latino population over the decade. Among neighborhoods of black concentration, the average percentage of blacks declined notably, from 27.9 in 2000 to 21.1 in 2005-09, likely a result of both black out-migration from centralized neighborhoods into more peripheral ones and in-migration of nonblacks into centralized neighborhoods. Block groups of concentrated poverty had a combined average of 28.7 percent of households below poverty in 2000, and 27.5 percent below poverty in 2005-09 with an increase of six high-poverty neighborhoods over the decade.

Segregated black and high poverty neighborhoods showed higher percentages of characteristics associated with dense urban environments, including the neighborhood's percentage of renters and zero-vehicle households (Table 2). Most notably, in both 2000 and 2005-09, block groups of concentrated poverty were most densely populated among segregated neighborhood types, and segregated black block groups showed the second highest density. For both of these categories, average population density for block groups declined slightly across the decade, providing further evidence of the decentralization of poor and minority residents.

\section{MULTIVARIATE RESULTS}

The multivariate analysis uses Poisson regression to explore the effect of the three explanatory variables of interest-Latino segregation, black segregation, and concentrated poverty - on the block group-level dependent variable, transit route choice, after controlling for the effects of socioeconomic and built environment factors. Segregated black and Latino neighborhoods showed similar directional shifts in levels of transit access across years (Table 3). Both neighborhood types declined in transit access over the decade, but Latino neighborhoods were comparatively disadvantaged in transit access in both years, while black neighborhoods showed comparatively high levels of transit access relative to other neighborhoods, despite a decline in access since 2000.

In 2000 and 2005-09, block groups of black concentration showed a higher number of expected transit route choices than other block groups, but their relative advantage 
TABLE 3. Multivariate Results for Census 2000 and ACS 2005-09: Incidence Rate Ratios (Poisson regression) for Average Number of Accessible Transit Routes for Block Groups

\begin{tabular}{|c|c|c|c|c|}
\hline \multirow[b]{2}{*}{ Independent variables } & \multicolumn{2}{|c|}{$\begin{array}{l}\text { Number of Accessible } \\
\text { Transit Routes } \\
\text { (Census 2000) }\end{array}$} & \multicolumn{2}{|c|}{$\begin{array}{c}\text { Number of Accessible } \\
\text { Transit Routes } \\
\text { (ACS 2005-09) }\end{array}$} \\
\hline & $I R R$ & $S E$ & $I R R$ & $S E$ \\
\hline Population density & $1.018^{*}$ & 0.002 & $1.036^{*}$ & 0.002 \\
\hline Job count & 0.986 & 0.011 & 1.006 & 0.012 \\
\hline Percent working age population & $1.013^{*}$ & 0.002 & $1.027 *$ & 0.001 \\
\hline Percent postsecondary education & 1.000 & 0.001 & 1.001 & 0.001 \\
\hline Percent renters & $1.007 *$ & 0.001 & $1.009 *$ & 0.001 \\
\hline Percent households with no vehicle & $1.014^{*}$ & 0.001 & $0.991 *$ & 0.002 \\
\hline Segregated Latino neighborhood & $0.803^{*}$ & 0.039 & $0.719 *$ & 0.035 \\
\hline Segregated black neighborhood & $1.333^{*}$ & 0.055 & $1.232 *$ & 0.059 \\
\hline High poverty neighborhood & $0.849 *$ & 0.037 & 1.008 & 0.036 \\
\hline Log likelihood & $-3,290$ & & $-2,696$ & \\
\hline Chi square & 1,749 & & 1,461 & \\
\hline Number of block groups & 823 & & 832 & \\
\hline
\end{tabular}

Significance level: $* p<.05$ (two-tailed tests).

in transit access declined across the decade. Segregated black block groups went from 30 percent more likely than all other block groups to live near transit in 2000 to about 20 percent more likely to live near transit in 2005-09. During this period such neighborhoods became more geographically dispersed, especially eastward toward neighborhoods where rail access is poor relative to that enjoyed by rapidly transitioning historically black neighborhoods. Figures 1 and 2 show the spatial relationship between segregated neighborhoods and the Portland metro area's light rail lines. To aid visual interpretation, the extensive network of bus routes is not included in the map, but bus routes are included in the transit access analysis.

In 2000, block groups of Latino concentration were expected to have access to about 20 percent fewer transit route choices relative to other block groups. This disadvantage became more severe over the decade, as block groups of Latino concentration in 2005-09 were associated with about 28 percent fewer transit route choices. This decline in transit access reflects the high degree of Latino concentration outside of the city center prior to 2000 and the subsequent formation of Latino enclaves both outside of Portland and within the city of Portland's peripheral neighborhoods.

Neighborhoods of concentrated poverty were associated with a relative disadvantage in transit access in 2000; they had about 15 percent fewer expected transit route choices relative to other block groups. Although block groups of concentrated poverty became more prevalent in suburbs over the course of the decade, the significance of the relationship between high-poverty block groups and transit access disappeared in 2005-09. The lack of a significant link between concentrated poverty and transit access in 2005-09 may be the result of several factors, such as the construction of new housing dedicated to low-income populations in transit-rich neighborhoods, extensions of rail lines, and associated feeder buses to outlying areas over the 2000s, or the introduction of new residents into the area who are poor but educated and have a strong commitment to living near the city center. Future research is needed to clarify this pattern and perhaps identify the influence of Portland's young and highly educated, but relatively low-income population on shifting wealth concentration and transit access. 


\section{DISCUSSION}

Observed reductions in transit access for segregated black and Latino neighborhoods illuminate the persisting relative disadvantage of areas of concentrated racial and ethnic minorities in neighborhood access to amenities. To reach transit by foot, people negotiate obstacles such as busy and dangerous intersections, poor street lighting, and limited sidewalk availability. Variation in these neighborhood characteristics may influence the real and perceived ease of accessing transit for homeowners and renters. Mechanisms that influence residential patterns, including transportation considerations, operate on a small geographic scale. With this project's robust transit access measure, small scale changes in group-level transit access become apparent.

The racial composition of several transit-rich neighborhoods in Portland, many of which are historically black neighborhoods, is quite mixed, but this heterogeneity may represent a temporarily integrated state during a period of transition. Among block groups of black concentration, the average percentage of black residents has declined from 28 percent in 2000 to 21 percent in 2005-09. Several block groups with high absolute and relative proportions of blacks in 2000 were majority white by 2005-09. Among all block groups with transit access scores of 10 or more routes, the total number of blacks declined from 23,384 to 15,766 .

Newly formed segregated Latino and high-poverty neighborhoods have largely emerged within inner suburbs. Several of the earliest Latino enclaves such as Hillsboro formed within close proximity to suburban transit stops and enjoyed relatively good transit access in 2000. These earliest enclaves continued to enjoy reasonable transit access in 2005-09, but throughout the decade have expanded into adjacent block groups, away from transit hubs. This decentralization pattern provides one explanation for the observed reduction in transit access across the decade for block groups of Latino concentration.

High-poverty block groups also became less centralized, but several of them that formed since 2000 were located near transit hubs in outlying communities such as Milwaukie, Aloha, Powellhurst, and Gresham. This may partially explain the lack of a significant relationship between high poverty block groups and transit access in 2005-09. Even in suburbs with numerous transit options, the monetary and time costs of transit trips to the central city, where employment is concentrated, are relatively high.

A growing number of studies concerned with the spatial distribution of opportunity have taken the important step of considering how transportation choices affect access to jobs and other amenities for low-income people and racial and ethnic minorities (Kawabata and Shen 2007; Tomer 2012). Still, this line of academic inquiry has not assessed changes in transit access over time and across population groups. This should be of increasing importance for spatial mismatch studies as investment in central cities increases, along with the economic well-being of their residents. This study shows that the advantage in proximity to transit enjoyed by economically disadvantaged groups due to their central location may weaken in some communities. While this may reflect the breaking down of racial barriers and more suburban housing opportunity for some low-income people, it may reflect displacement from the urban core for others. In Portland, black and high-poverty enclaves still enjoy favorable access to transit, but this pattern may be a remnant of historic social and economic forces that have relegated the poor to neighborhoods where transit usage is associated more with financial need than an amenity with widespread appeal. 
As spatial shifts in the distribution of wealth continue across metropolitan landscapes, the appeal of transit and other amenities associated with urban living will likely become attractive to a wider socioeconomic spectrum of city dwellers. Many of the metro areas where gentrification has been most severe are also home to some of the nation's most extensive transit systems. These include such places as New York City, Washington, DC, and San Francisco. Assessments of equity in the distribution of amenities across places should consider not just the relative distribution of amenities, but also the absolute level of access across groups and the minimum level of access for those worse off (Van Wee and Geurs 2011). With this in mind, Portland offers a relatively high absolute level of transit access across neighborhoods when compared to other relatively small metropolitan areas and larger ones with a higher degree of suburban sprawl. More research is needed to illuminate relationships between transit access and residential patterns across metro areas and population groups.

As competition for transit access increases, the neighborhood benefits of improved public transportation infrastructure may become increasingly inaccessible to those with the fewest resources. Finding a home near transit may be particularly difficult for blacks and Latinos, who have lower average incomes than non-Hispanic whites and still face discriminatory barriers that limit residential choice (Massey and Denton 1993; Hogan and Berry 2011). Creating and retaining affordable housing and investing in transit infrastructure within the nation's expanding suburbs will be crucial to expanding transportation choice for all residents of our shared built environments. Urban scholarship should rethink the SMH and elevate research on the role of transit access and transit-based mobility in providing equal opportunity.

The limited availability of spatial data in prior decades hinders the quality and accuracy of retrospective transit access analysis at small geographies, but the prospects of future longitudinal transit access analyses are promising for several reasons. First, the availability and quality of spatial data improved considerably over the 2000s, and an increasing number of planning authorities at various levels invested resources into developing regional data. Second, nonoverlapping American Community Survey estimates will soon be available, providing more frequent data points than the decennial Census, and at small geographies. As issues of mobility and transportation choice become more integral to the discussion of access to opportunity, scholarship should work toward developing typologies of access issues and examine communities with varied characteristics. This research speaks to transit access in a region with a relatively robust urban core, a strong commitment to multimodal transportation investment, and relatively high population density. More research is needed to determine how issues of transit access work in communities with very different characteristics such as sprawl and very high automobile dependence.

\section{CONCLUDING REMARKS}

An urban growth boundary to curb sprawl, a vibrant urban core, and a relatively high rate of transit usage are among the many well-documented planning achievements of the Portland, OR, region. The region's growth management efforts and investment in transit and other alternative forms of transportation represent positive shifts toward more equitable metropolitan landscapes. Nonetheless, this study finds a propensity for relative declines in transit access for population groups that traditionally have heavily relied on it. 
This tendency may be especially severe in metropolitan areas experiencing intense competition for central city housing. Increased centralized housing costs have pushed many economically disadvantaged people into less expensive, sometimes amenity-deprived suburbs, many of which offer few reasonable transportation options other than the automobile.

The Portland, OR, region's block groups of high Latino concentration already had poor transit access relative to other neighborhoods in 2000, and they experienced further declines in transit access by 2005-09. Neighborhoods of black concentration are more centrally located than their segregated Latino counterparts and had relatively high levels of transit access in both years but like Latinos, experienced relative and absolute declines in transit access during the 2000s. Within several historically black transit-rich neighborhoods, the proportion and, for several block groups, absolute number of black residents declined across the decade, meaning that a smaller proportion of the region's black population lives in transit-rich neighborhoods. These findings suggest that race and ethnicity remain salient bases of residential sorting and continue to shape spatial differences in access to the most desirable public resources.

Beyond its substantive findings, this study makes methodological contributions to the literature. It focuses on changes in transit access over time, rather than a single temporal snapshot, and employs an innovative approach to measuring transit access, accounting for the spatial distribution of all households within a block group rather than a single neighborhood point. It also uses a sidewalk network approach to measure walking distance between households and transit stops rather than the less accurate, but more commonly used straight-line distance approach. The methods used in this study have several natural applications beyond the transportation research domain.

The relegation of the poor and racial and ethnic minorities to amenity-deprived neighborhoods with poor transit options will likely perpetuate and even exacerbate socioeconomic disparities. People with few resources and housing choices must creatively negotiate travel across landscapes that offer relatively few inexpensive travel options. Transit has the potential to link low-income populations to jobs and other resources that are often concentrated in wealthier neighborhoods. However, the spatial structure of employment relative to residence in metropolitan areas has changed since the original SMH. In this period of increased austerity, policy makers and planners must employ creative mechanisms to increase the range of efficient travel options that accommodate a wider range of incomes and racial mixes of neighborhoods. Efforts should also be made to preserve a certain level of affordable housing in areas that disproportionately benefit from public infrastructure investment that is likely to attract gentrification and rapidly increase the cost of housing.

Transit ridership reached record highs in 2012, despite numerous transit system cuts across the nation (APTA 2013). Many local governing bodies and private developers appear interested in the social justice and market possibilities of transit-oriented development, but implementation has been slow for many regions, even with increased transit demand. Widespread progress toward increasing transportation choices requires a heretofore unrealized public commitment to substantial infrastructural investment in transit and the travel modes and housing that supplement it. As suburbs increasingly become home to the poor and those with limited residential choices, transit-oriented housing investment should extend beyond the nation's large and dense central cities to accommodate more of the rapidly growing suburban transit demand. It is here that the need 
for affordable transportation options will grow rapidly among the poor, the elderly, and other groups that will disproportionately rely upon transit access.

\section{Acknowledgments}

This research is an extension of work completed at the State University of New York at Albany. Any views or opinions expressed in this article are those of the author and do not necessarily reflect those of the U.S. Census Bureau.

\section{REFERENCES}

Alam, Bhuiyan Monwar. 2005. "Influence of Transit Accessibility to Jobs on the Employability of the Welfare Recipients: The Case of Broward County, Florida." Electronic Dissertation. Paper 45. http://diginole. lib.fsu.edu/etd/45.

Alba, Richard, Nancy A. Denton, Donald J. Hernandez, Ilir Disha, Brian McKenzie, and Jeffrey Napierala. 2010. "Nowhere Near the Same: The Neighborhoods of Latino Children." Pp 3-48 in Growing Up Hispanic: Health and Development of Children of Immigrants, edited by Nancy S. Landale, Susan McHale, and Alan Booth. Washington, DC: The Urban Institute Press.

Allard, Scott W., and Benjamin Roth. 2010. Strained Suburbs: The Social Service Challenges of Rising Suburban Poverty. Washington, DC: Brookings Institution.

American Planning Association (APA). 2012. Planning in America: Perceptions and Priorities. APA website. Retrieved July 2, 2012, from www.planning.org-/policy/economicrecovery/.

American Public Transportation Association (APTA). 2013. Public Transportation Ridership Report: Fourth Quarter 2012. Retrieved March 22, 2013, from www.apta.com/resources/statistics/documents/ridership/ 2012-q4-ridership-apta.pdf.

Bader, Michael D.M., Jennifer D. Ailshire, Jeffrey D. Morenoff, and James S. House. 2010. "Measurement of the Local Food Environment: A Comparison of Existing Data Sources.” American Journal of Epidemiology 171:609_ 617.

Becker, Sofia, Scott Bernstein, and Linda Young. 2013. The New Real Estate Mantra: Location Near Public Transportation. Washington, DC: American Public Transportation Association.

Cervero, Robert, Juan Onesimo Sandoval, and John Landis 2002. "Transportation as a Stimulus of Welfare-to Work: Private versus Public Mobility,” Journal of Planning Education and Research 22:50-63.

Chakraborty, Arnab, Gerrit-Jan Knaap, Doan Nguyen, and Jung Ho Shin. 2010. "The Effects of High-density Zoning on Multifamily Housing Construction in the Suburbs of Six US Metropolitan Areas." Urban Studies 47:437-51.

Covington, Kenya. 2009. "Spatial Mismatch of the Poor: An Explanation of Recent Declines in Job Isolation." Journal of Urban Affairs 31:559-87.

Dwyer, Rachel E. 2010. "Poverty, Prosperity, and Place: The Shape of Class Segregation in the Age of Extremes." Social Problems 57:114-37.

Ellen, Ingrid Gould, Karen Horn, and Katherine O'Regan. 2012. Pathways to Integration: Examining Changes in the Prevalence of Racially Integrated Neighborhoods. Presentation at the Cityscape Residential Mobility Symposium. Retrieved April 14, 2013, from www.urban.org/Presentations/CityScape/CScapeEllen.pdf.

Frey, William. 2011. Melting Pot Cities and Suburbs: Racial and Ethnic Change in Metro America in the 2000s. Washington, DC: Brookings Institution.

Grengs, Joe. 2001. "Does Public Transit Counteract the Segregation of Carless Households? Measuring Spatial Patterns of Accessibility." Transportation Research Record 1753:3-10.

—. 2010. "Job Accessibility and Modal Mismatch in Detroit." Journal of Transport Geography 18:42-54.

Hogan, Bernie, and Brent Berry. 2011. "Racial and Ethnic Biases in Rental Housing: An Audit Study of Online Apartment Listings." City Eं Community 10:351-72.

Holzer, Harry J., and John Quigley. 2003. "Public Transit and the Spatial Distribution of Minority Employment: Evidence from a Natural Experiment." Journal of Policy Analysis and Management 22:415-42.

Holzer, Harry J., and Michael A. Stoll. 2007. Where Workers Go Do Jobs Follow? Metropolitan Labor Markets in the US, 1990 to 2000. Washington, DC: Brookings Institution.

Ihlanfeldt, Keith, and David Sjoquist. 1998. "The Spatial Mismatch Hypothesis: A Review of Recent Studies and Their Implications for Welfare Reform.” Housing Policy Debate 8:849-92. 


\section{CITY \& COMMUNITY}

Kahn, Mathew E. 2007. "Gentrification Trends in New Transit-Oriented Communities: Evidence from 14 Cities That Expanded and Built Rail Transit Systems." Real Estate Economics 35:155-82.

Kain, John F. 1968. "Housing Segregation, Negro Employment, and Metropolitan Decentralization." Quarterly Journal of Economics 82:175-97.

Kawabata, Mizuki, and Qing Shen. 2007. "Commuting Inequality between Cars and Public Transit: The Case of San Francisco Bay Area, 1990-2000.” Urban Studies 44:1759-80.

Kneebone, Elizabeth, and Emily Garr. 2010. The Suburbanization of Poverty: Trends in Metropolitan America, 2000 to 2008. Washington, DC: Brookings Institution.

Kneebone, Elizabeth, Carey Nadeau, and Alan Berube. 2011. The Re-Emergence of Concentrated Poverty: Metropolitan Trends in the 2000s. Washington, DC: Brookings Institution.

Leinberger, Christopher B., and Mariela Alfonzo. 2012. Walk This Way: The Economic Promise of Walkable Places in Washington, DC. Washington, DC: Brookings Institution.

Liu, Cathy Yang. 2009. "Ethnic Enclave Residence, Employment, and Commuting of Latino Workers." Journal of Policy Analysis and Management 28:600-25.

Logan, John R, and Brian J. Stults. 2010. Racial and Ethnic Separation in the Neighborhoods: Progress at a Standstill. US2010 Project. www.s4.brown.edu/us2010/Projects-/Reports.htm.

Luce, Thomas, Myron Orfield, and Jill Mazullo. 2006. "Access to Growing Job Centers in the Twin Cities Metropolitan Area." CURA Reporter 36:3-12.

Lucy, William H. 2010. Foreclosing the Dream: How America's Housing Crisis is Reshaping our Cities and Suburbs. Washington, DC: American Planning Association.

Massey, Douglas S., and Nancy A. Denton. 1993. American Apartheid: Segregation and the Making of the Underclass. Cambridge: Harvard University Press.

Mayer, Heike. 2005. "Taking Root in the Silicon Forest: High Technology Firms as Surrogate Universities in Portland, OR.” Journal of the American Planning Association 71:318-33.

McKenzie, Brian, and Melanie Rapino. 2011. Commuting in the United States: 2009, American Community Survey, ACS-15. Washington, DC: U.S. Census Bureau.

Miles, Rebecca, and Yan Song. 2009. 'Good' Neighborhoods in Portland, Oregon: Focus on Both Social and Physical Environments.” Journal of Urban Affairs 31:491-509.

Nechyba, Thomas. 2003. "School Finance, Spatial Income Segregation, and the Nature of Communities." Journal of Urban Economics. 54:61-88.

Neckerman, Kathryn, Michael Bader, Marnie Purciel, and Paulette Yousefzadeh. 2009. "Measuring Food Access in Urban Areas." Paper presented at Understanding the Economic Concepts and Characteristics of Food Access, USDA, Washington, DC.

Newbold, Bruce, and John Spindler. 2001. "Immigrant Settlement Patterns in Metropolitan Chicago." Urban Studies 38:1903-19.

Ong, Paul, and Douglas Houston. 2002. "Transit, Employment, and Women on Welfare." Urban Geography 23:344-64.

Parks, Virginia. 2004. "The Gendered Connection Between Ethnic Residential and Labor Market Segregation in Los Angeles.” Urban Geography 25:589-30.

Phillips, Justin, and Eban Goodstein. 2000. "Growth Management and Housing Prices: The Case of Portland, Oregon.” Contemporary Economic Policy 18:334-44.

Raja, Samina, Changxing Ma, and Padan Yadav. 2008. "Beyond Food Deserts: Measuring and Mapping Racial Disparities in Neighborhood Food Environments." Journal of Planning Education and Research 27:469-82.

Raphael, Steven, and Michael Stoll. 2010. Job Sprawl and the Suburbanization of Poverty. Washington, DC: Brookings Institution.

Reardon, Sean, and Kendra Bischoff. 2011. Growth in the Residential Segregation of Families by Income, 1970-2009. US2010 Project. www.s4.brown.edu-/us2010/projects/.

Roberto, Elizabeth. 2007. Commuting to Opportunity: The Working Poor and Commuting in the United States. Washington, DC: Brookings Institution.

Sanchez, Thomas W. 1999. "The Connection Between Public Transit and Employment: The Cases of Portland and Atlanta." Journal of the American Planning Association 65:284-96.

2002. "The Impact of Public Transport on U.S. Metropolitan Wage Inequality." Urban Studies 39:423-36.

Sanchez, Thomas W., Qing Shen, and Zhong-Ren Peng. 2004. "Transit Mobility, Jobs Access and Low-Income Labor Market Participation in U.S. Metropolitan Areas." Urban Studies 41:1313-31.

Shaw, Samuel, and Daniel Sullivan. 2011. "White Night': Gentrification, Racial Exclusion, and Perceptions and Participation in the Arts." City $\mathcal{E}$ Community 11(3):241-64. 
Singer, Audrey. 2010. The State of Metropolitan America: Immigration. Washington, DC: Brookings Institution.

Song, Yan, and Gerrit Knaap. 2004. "Measuring Urban Form: Is Portland Winning the War on Sprawl?" Journal of American Planning Association 70:210-25.

Sparks, Andrea, Neil Bania, and Laura Leete. 2011. "Comparative Approaches to Measuring Food Access in Urban Areas: The Case of Portland, Oregon." Urban Studies 48:1715-37.

Stoll, Michael, Harry Holzer, and Keith Ihlanfeldt. 2000. "Within Cities and Suburbs: Racial Residential Concentration and the Spatial Distribution of Employment Opportunities across Metropolitan Areas." Journal of Policy Analysis and Management 19:207-31.

Stoll, Michael. 2006. "Job Sprawl, Spatial Mismatch and Black Employment Disadvantage." Journal of Policy Analysis and Management 25:827-54.

Sullivan, Daniel Monroe. 2007. "Reassessing Gentrification: Measuring Residents' Opinions Using Survey Data." Urban Affairs Review 42:583-92.

Sullivan, Daniel Monroe, and Samuel C. Shaw. 2011. "Retail Gentrification and Race: The Case of Alberta Street in Portland, Oregon." Urban Affairs Review 47:413-32.

Taylor, Brian D., and Paul M. Ong. 1995. "Spatial Mismatch or Automobile Mismatch? An Examination of Race, Residence, and Commuting in U.S. Metropolitan Areas." Urban Studies 32:1453-1473.

The Changing Colour of Cities: Black Flight. March 31, 2011. Economist.

Thompson, Gregory L., and Jeffrey R. Brown. 2012. "Making a Successful LRT-Based Regional Transit System: Lessons from Five New Start Cities.” Journal of Public Transportation 15:157-80.

Tomer, Adie. 2011. Transit Access and Zero-Vehicle Households. Washington, DC: Brookings Institution.

- 2012. Where the Jobs Are: Employer Access to Labor by Transit. Washington, DC: Brookings Institution.

TriMet. 2012. "Trimet News Releases and Media Resources." Retrieved July 8, 2012, from http://trimet.org/ news/releases/feb8-budget-proposal.htm.

U.S. Census Bureau. 2011. “American FactfinderII, detailed tables.” Retrieved November 11, 2011, from www.factfinder2.census.gov.

- 2012. Quickfacts. Retrieved January 2, 2012, from http:/ / quickfacts.census.gov.

Van Wee, Bert, and Karst Geurs. 2011. "Discussing Equity and Social Exclusion in Accessibility Evaluations." European Journal of Transport and Infrastructure Research 11:350-367.

Wagmiller, Robert. 2007. "Race and the Spatial Segregation of Jobless Men and Urban America." Demography 44:539-62.

Wilson, William J. 1996. When Work Disappears: The World of the New Urban Poor. New York: Knopf.

Yang Liu, Cathy, and Gary Painter. 2012. "Immigrant Settlement and Employment Suburbanization in the U.S.: Is There a Spatial Mismatch?” Urban Studies 49:979-1002.

\section{Acceso al Tránsito por Raza, Etnicidad y Pobreza en Portland, Oregon (Brian S. McKensie)}

\section{Resumen}

Discusiones académicas sobre accesibilidad y el "desajuste espacial" (spatial mismatch) ignoran el rol del transporte en conectar a las poblaciones vulnerables a distintas oportunidades. Mientras la población de ingresos más bajos se ha vuelto más suburbana en las últimas décadas, el acceso al transporte podría tornarse en un bien de alto valor pero más escaso en términos de oportunidades para aquellos con menores recursos y opciones de vivienda. Este estudio explora diferencias en acceso al transporte en barrios con mayor concentración de usuarios de transporte masivo. Usando información del Censo del año 2000 y de 5 años de la Encuesta de Comunidades Americanas (ACS), se comparan cambios en el nivel de acceso al transporte en barrios con alta concentración de población negra, latina y pobre en Portland, OR. Los resultados muestran que los barrios de alta concentración de latinos en Portland tienen el peor acceso al transporte en términos relativos. Más aún, los niveles de acceso al transporte bajaron en los barrios con alta concentración de población negra y latina durante el periodo de estudio. 